\title{
Assisted Migration
}

Synthesis prepared for the USDA Forest Service Climate Change Resource Center. 2018.

How to cite: Handler, S.; Pike, C.; St. Clair, B.; 2018. Assisted Migration. USDA Forest Service

Climate Change Resource Center. https://www.fs.usda.gov/ccrc/topics/assisted-migration

\section{Preparers}

- Stephen Handler, Northern Institute of Applied Climate Science, US Forest Service Northern Research Station, Houghton, MI.

- Carrie Pike, US Forest Service Northeastern Area, West Lafayette, IN.

- Brad St. Clair, US Forest Service Pacific Northwest Research Station, Corvallis, OR.

- Hannah Abbotts, Northern Institute of Applied Climate Science, Michigan Technological University, Houghton, MI.

- Maria Janowiak, Northern Institute of Applied Climate Science, US Forest Service Northern Research Station, Houghton, MI.

\section{Scientific Background}

Evidence suggests that species have responded individually during historic periods of dramatic climate change through geographic migrations to and from unique glacial refugia $[1,2,3]$. Recent research has demonstrated that many tree species are already undergoing distribution shifts in response to climate change, with different studies highlighting species that are moving poleward and higher in elevation [4], or moving east-west to track changes in moisture availability [5]. 
Many factors can complicate species movement across a fragmented landscape, however, so outcomes of climate change may not follow straightforward expectations. Large-scale FIA studies have revealed that many tree species in the eastern US may be experiencing range contraction at northern and southern range limits [6]. Research on Douglas-fir and ponderosa pine indicates that different genetic subspecies and local populations within a given species may have individual responses to climate change and different levels of vulnerability [7]. Ecosystem succession following the era of intensive logging and human land-use changes have both been suggested as factors to explain tree species migrating downslope in New England mountains in recent decades [8]. Similarly, wildfire suppression practices may have also contributed to observed tree species movement in the eastern US, and species from different taxonomic groups are likely responding differently [5].

Despite the complexities of forecasting species range shifts into the future, the underlying challenge still remains that many species will face extinction or local extirpation if they do not acclimate, adapt via natural selection, or migrate to new suitable habitats as conditions change. Given the observed and projected rates of change, there is a substantial risk that some species will be unable to migrate quickly enough to track change [9]. Natural migration over long distances requires several generations, and this process is slow because trees require several years to get to reproduction age, and regeneration opportunities may be limited for a variety of reasons. Recent estimates indicate that post-glacial migration rates for many tree species were 100 to 500 meters per year $[10,11]$. Recent rates of change for particular locations in the US have been even more dramatic, with rates of change from 1,000 to 10,000 meters per year for large areas of the Midwest, Great Plains, and Southeast, as well as isolated locations in the western US [12]. These distances are a function of climate change rates ("climate velocity") and spatial climatic variation due to topography.

For species with very specific habitat needs or ranges limited by physical barriers, such as fragmentation or geographic features, this may mean that the entire species could be at risk of extinction or extirpation due to climate change [13]. In the case of widespread species, complete 
loss of the species may not be a risk; however, climate change may result in large-scale mortality and population extirpation due to maladaptation of populations.

Studies involving reciprocal transplants of different species along large gradients have demonstrated the potential for assisted migration to benefit tree species and local populations. For example transplant studies of white spruce in Quebec showed that physiological traits such as photosynthetic rate and stomatal conductance were relatively plastic between populations and suggested that southern seed sources might be used in northern locations to increase growth and productivity without sacrificing seedling survival [14]. Promising results have been demonstrated for species with more restricted ranges as well. Trials with whitebark pine demonstrated that seeds can be successfully germinated and grown large distances ( $800 \mathrm{~km}, 500$ miles) to the north of the current species range boundary - seed sources from Oregon and Washington performed well in locations in northwestern British Columbia [15]. These studies, and others, have demonstrated that assisted migration is a reasonable option to help populations and species occupy areas of projected suitable habitat under climate change.

Furthermore, assisted migration doesn't necessarily need to be implemented as a widespread action to be successful. Even if small founder populations of individuals can survive beyond existing ranges, they may contribute genetic diversity associated with warmer climates to native populations such that the native populations might have a better chance to adapt through natural selection [16].

\section{Definitions}

Assisted migration, human-assisted movement of species in response to climate change, is a general term that encompasses a variety of different potential actions, which have substantial differences in terms of risk, ecological implications, and policy considerations. Here are some of the commonly used terms that distinguish between different forms of assisted migration [11]:

- Assisted population migration (also assisted genetic migration or assisted gene flow) moving seed sources or populations to new locations within the historical species range 
- Assisted range expansion - moving seed sources or populations from their current range to suitable areas just beyond the historical species range, facilitating or mimicking natural dispersal

- Assisted species migration (also species rescue, managed relocation, or assisted longdistance migration) - moving seed sources or populations to a location far outside the historical species range, beyond locations accessible by natural dispersal

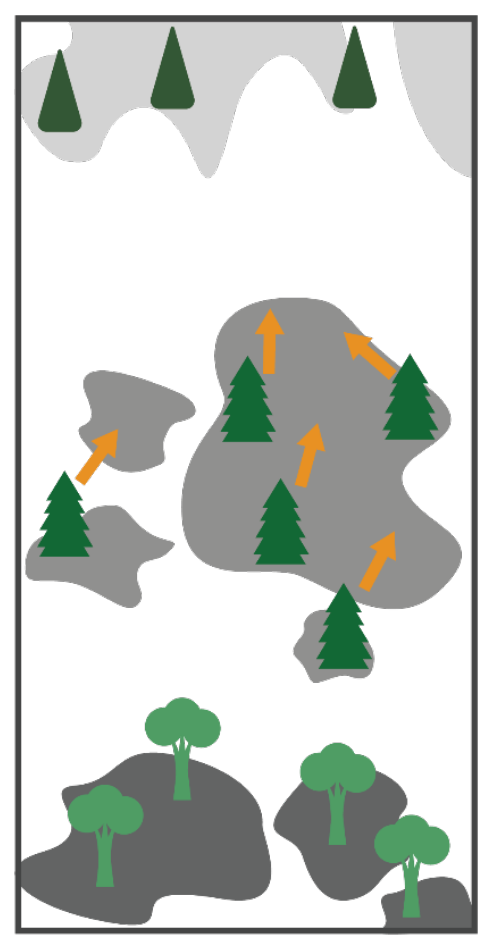

Assisted Population Migration

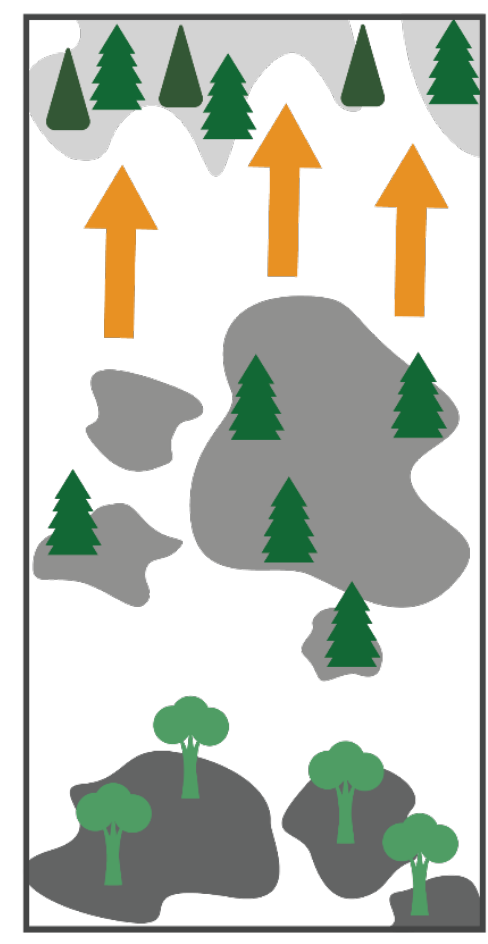

Assisted Range Expansion

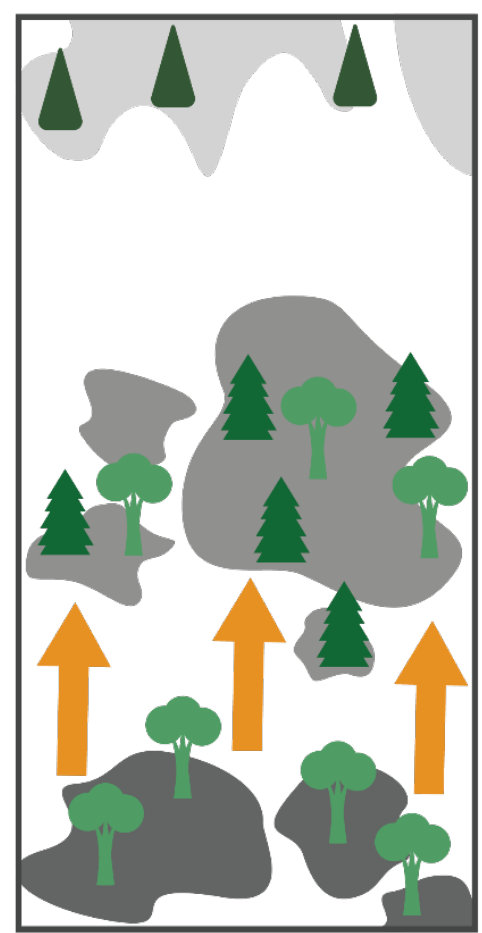

Assisted Species Migration

\section{Management Considerations}

Assisted migration may be motivated by a variety of different management goals and objectives. Clarifying management intent should be the first step in considering how or if to pursue assisted migration, whether the goal is to maintain or enhance genetic diversity within a population, protect a species or population from extinction, mimic natural dispersal interrupted by human habitat barriers, maintain ecosystem functions, or enhance the productivity of a commercially valuable 
species. Clearly articulated management goals and objectives will help determine which kinds of assisted migration actions are most suitable (see above definitions) and also help evaluate the benefits and risks.

A land manager may first need to make decisions about which species are appropriate to favor in a given area. Will the current and future climate pose risks to any existing species, and will it be necessary to supplement the existing species composition through assisted migration? Secondly, a manager may need to consider appropriate seedlots or seed sources within populations. There may be populations within a species that are more suited to expected climate conditions, and acquiring seed sources from those populations may help the species perform well into the future. New tools exist to help foresters with both of these decisions, namely the Climate Change Tree Atlas, and ForeCASTS for species-level considerations and the Seedlot Selection Tool for seedlot and seed source considerations.

Assisted migration raises legitimate concerns with respect to economic practicality, ecological suitability, and legal or administrative barriers [17] . In some cases, the concept of assisted migration will directly conflict with established conservation principles (e.g., the precautionary principle) and existing agency policy (e.g. Forest Service seed transfer zones). In some cases, however, it is clear that climate change and other conservation challenges make the risk associated with doing nothing greater than the risk associated with intervening.

Briefly, some of the important management challenges and opportunities include:

\section{Challenges:}

- Newly introduced species may become invasive

- The potential exists for newly introduced species to hybridize with local species, particularly within certain genera with species pairs capable of interspecific hybridization, including spruce (Picea), pine (Pinus), poplar (Populus), and oak (Quercus) [10]

- Species introductions may unknowingly introduce pests or diseases into new areas, particularly with longer transfer distances 
- Long-distance transfers based on projected climate conditions at the end of the century raise the likelihood that current habitat may not be suitable, which could result in poor growth or planting failure

- Species have different patterns of genetic diversity and plasticity, so some species will have smaller climatic transfer limits than others. For example, Douglas-fir and lodgepole pine may have smaller transfer limits than eastern white pine

- Genetically diverse seed sources and sufficient quantities of seed may not currently exist for species with limited ranges or for species that are not commercially utilized

- Assisted migration may be more costly to implement at scale than traditional regeneration practices, especially in situations where natural regeneration is commonly practiced. These costs will include cone and seed collection, orchard development, and additional infrastructure

- Site factors other than climate, such as soil type, moisture regime, herbivory, competition, endemic pests and pathogens, and photoperiod may preclude successful establishment [18]

\section{Opportunities:}

- Assisted population migration and assisted range expansion may help maintain forest productivity under climate change, particularly when suitable seed sources or populations are moved to locations within, or just beyond, the historical range

- Assisted population migration and assisted range expansion may not add much cost to existing practices of forest regeneration for species that are routinely planted [19]

- Provenance trial data are available for many widespread, commercially valuable tree species, which will help managers make informed decisions about the performance of seed sources from outside their local area

- The genetic diversity of seed orchards can be controlled or increased to provide a suitable seed source for commercially valuable trees 
- Assisted migration can help maintain crucial ecosystem functions (wildlife habitat, carbon sequestration, etc.), particularly when local species are already declining or are anticipated to decline in the future

- Assisted species migration (species rescue) can help "lifeboat" a species or population that is in critical risk

- Assisted migration can help ensure that a species occurs in many redundant locations or across a range of conditions, which helps reduce risk from uncertain climate impacts

- Assisted migration can help populations and species move across ecological barriers in fragmented landscapes

Some species and/or populations may warrant a higher priority for assisted migration. For example, species that are rare, have limited genetic variation, or have low dispersal rates may be especially vulnerable to climate change [13]. At the population level, small populations, populations in fragmented landscapes, or populations at the trailing edge of the specie range may be most at risk [13] .

\section{Current Applications}

The movement of species and populations has been practiced extensively across the landscape, considering indigenous movement of focal species, forest plantations for timber production, and informal experimentation in small-scale projects. While recognizing this history, the land management community is still in the early stages of applying assisted migration specifically as a climate change adaptation strategy. Useful examples of assisted migration that can inform management decisions range from long-term field trials such as provenance tests, to programmatic agency responses, to less formal management-oriented examples.

The Assisted Migration Adaptation Trial (AMAT), led by the British Columbia Ministry of Forests, Lands, Natural Resource Operations, and Rural Development working with the USDA Forest Service, timber companies, and other partners, is a long-term research project that is testing climate tolerances of different seedlots across a broad territory from northern California to the southern 
Yukon. (https://www2.gov.bc.ca/gov/content/industry/forestry/managing-our-forest...).

Researchers are testing the growth and health of seedlings from 15 different species, including ponderosa pine, lodgepole pine, western larch, yellow cedar, and Douglas-fir. Information from this project will be used to revise formal tree species and seed source selection guidelines for British Columbia.

The Adaptive Silviculture for Climate Change (ASCC) project is one example of a field trial that involves assisted migration as a climate adaptation action on Forest Service lands and other ownerships (www.adaptivesilviculture.org) [20] . ASCC study locations around the country are designed to represent a range of climate adaptation pathways, including a proactive "transition" treatment. Transition treatments intentionally encourage a shift to a new species composition or ecosystem type that is designed to be better suited to end-of-century climate change conditions. For example, at the ASCC study location on the Cutfoot Experimental Forest on the Chippewa National Forest in northern Minnesota, the transition treatment included assisted migration of white oak, bitternut hickory, and ponderosa pine. These species movements represent movements of dozens of miles to hundreds of miles outside the natural range of these species. As this long-term study unfolds each of the research sites, managers will be able to learn how the different assisted migration actions perform.

Along with projects like AMAT and ASCC, which explore species-level assisted migration, many past and on-going research exists that examine questions of genetic variation within species and the effects of climatic transfer on growth and survival. For example, a large lodgepole pine project in British Columbia involving 140 distinct populations and 62 planting sites was able to establish a reliable basis for predicting the influence of climate on different lodgepole seed sources [21]. The Douglas-fir Seed Source Movement Trial in Oregon and Washington has revealed within-species differences in drought tolerance and cold hardiness, and more information is forthcoming [22, 23] . This kind of information will help managers make informed decisions about appropriate seedlots and avoid costly mismatches. Importantly, provenance tests established for other reasons have also proven to be useful for considering climate change responses. 
Within the USDA Forest Service, Regional Geneticists have recommended a "no regrets" approach to considering assisted migration and seed transfer as a climate adaptation strategy in the 2012 report Genetic Resource Management and Climate Change: Genetic Options for Adapting National Forests to Climate Change [13] . Population transfers to match seed sources to projected future conditions are recommended only for species where experience or research has demonstrated appropriate climate transfer limits. The authors of this report also discourage basing assisted migration decisions on long-term projections of climate conditions at the end of the century, but they advocate for using a 20-year time frame of climate projections as the basis for setting suitable transfer distances. This would tend to reduce risk of mismatches between seedlings moved from warmer to colder climates. National Forests are able to request permission to introduce novel species for assisted migration with longer transfer distances, but these actions are primarily permitted in limited situations for research purposes. The Southern Region of the US Forest Service is operationally mixing adjacent south-north seed zones in reforestation projects as a climate adaptation action.

Similarly, the Canadian Forest Service and Provincial forestry departments in Canada are encouraging limited use of assisted migration as a climate change adaptation practice. British Columbia began allowing seed transfers to higher altitudes in 2008 , and formally amended the Chief Forester's Standards for Seed Use policy in 2018 to allow for climate-based seed transfer [24]. Alberta, Ontario, and Quebec currently allow seed zone exceptions with appropriate review. In addition to these large-scale studies and programmatic responses, many foresters and land managers are exploring assisted migration on their own. Based on careful consideration of climate change risks, their management goals, and their ability to take risks, foresters are establishing many pilot-scale projects that involve some degree of assisted migration. For example, Providence Water is responsible for managing 13,000 acres of forested pubic land surrounding the state of Rhode Island's major freshwater reservoirs. For over a century, their overarching goal has been to maintain a forest that is resilient to disturbances that could negatively impact water quality. Many northern species in this property will face increasing stress from climate change, and so Providence Water is experimenting with assisted migration as a climate adaptation practice, planting southerly 
species such as black oak, black locust, persimmon, sweetgum, and others. Learn more about this project at www.forestadaptation.org/providence. These kinds of examples from early adopters will contribute valuable information as they are monitored through time.

\section{References:}

1. Petit, R.J.; Hu, F.S.; Dick, C.W. 2008. Forests of the past: A window to future changes. Science. 320(5882): 1450-1452.

2. Gonzales, L.M.; Williams, J.W.; Grimm, E.C. 2009. Expanded response-surfaces: a new method to reconstruct paleoclimates from fossil pollen assemblages that lack modern analogues. Quaternary Science Reviews. 28(27-28): 3315-3332.

3. Davis, M.B.; Shaw, R.G. 2001. Range shifts and adaptive responses to Quaternary climate change. Science. 292(5517): 673-679.

4. Chen, I.-C.; Hill, J.K.; Ohlemüller, R.; Roy, D.B.; Thomas, C.D. 2011. Rapid Range Shifts of Species Associated with High Levels of Climate Warming. Science. 333(6045): 1024-1026.

5. Fei, S.; Desprez, J.M.; Potter, K.M.; Jo, I.; Knott, J.A.; Oswalt, C.M. 2017. Divergence of species responses to climate change. Science Advances. 3(5).

6. Zhu, K.; Woodall, C.W.; Clark, J.S. 2012. Failure to migrate: lack of tree range expansion in response to climate change. Global Change Biology. 18(3): 1042-1052.

7. Rehfeldt, G.E.; Jaquish, B.C.; Sáenz-Romero, C.; Joyce, D.G.; Leites, L.P.; Bradley St Clair, J.; López-Upton, J. 2014. Comparative genetic responses to climate in the varieties of Pinus ponderosa and Pseudotsuga menziesii: Reforestation. Forest Ecology and Management. 324: 147-157.

8. Foster, J.R.; D'Amato, A.W. 2015. Montane forest ecotones moved downslope in northeastern USA in spite of warming between 1984 and 2011. Global Change Biology. 21(12): 4497-4507.

9. Groffman, P.; Kareiva, P.; Carter, S.; Grimm, N.; Lawler, J.; Mack, M.; Matzek, V.; Tallis, H. 2014. Ecosystems, Biodiversity, and Ecosystem Services. In: J. M. Melillo, T. T. C. Richmond and G. W. Yohe, eds. Climate Change Impacts in the United States: The Third National Climate Assessment. 8: U.S. Global Change Research Program: 195-219.

10. Aitken, S.N.; Yeaman, S.; Holliday, J.A.; Wang, T.; Curtis-McLane, S. 2008. Adaptation, migration or extirpation: climate change outcomes for tree populations. Evolutionary Applications. 1(1): 95 - 
111.

11. Williams, M.I.; Dumroese, R.K. 2013. Preparing for climate change: Forestry and assisted migration. Journal of Forestry. 111(4): 287-297.

12. Dobrowski, S.Z.; Abatzoglou, J.; Swanson, A.K.; Greenberg, J.A.; Mynsberge, A.R.; Holden, Z.A.; Schwartz, M.K. 2013. The climate velocity of the contiguous United States during the 20th century. Global Change Biology. 19(1): 241-251.

13. Erickson, V.; Aubry, C.; Berrang, P.; Blush, T.; Bower, A.; Crane, B.; DeSpain, T.; Gwaze, D.; Hamlin, J.; Horning, M.; Johnson, R.; Mahalovich, M.; Maldonado, M.; Sniezko, R.; Clair, B.S. 2012. Genetic Resource Management and Climate Change: Genetic Options for Adapting National Forests to Climate Change. In: U. F. Service, ed. Washington, DC: US Forest Service. 24.

14. Benomar, L.; Lamhamedi, M.S.; Rainville, A.; Beaulieu, J.; Bousquet, J.; Margolis, H.A. 2016. Genetic Adaptation vs. Ecophysiological Plasticity of Photosynthetic-Related Traits in Young Picea glauca Trees along a Regional Climatic Gradient. Frontiers in Plant Science. 7(48).

15. McLane, S.C.; Aitken, S.N. 2012. Whitebark pine (Pinus albicaulis) assisted migration potential: testing establishment north of the species range. Ecological Applications. 22(1): 142-153. 16. Aitken, S.N.; Whitlock, M.C. 2013. Assisted Gene Flow to Facilitate Local Adaptation to Climate Change. Annual Review of Ecology, Evolution, and Systematics. 44(1): 367-388.

17. Schwartz, M.W.; Hellmann, J.J.; McLachlan, J.M.; Sax, D.F.; Borevitz, J.O.; Brennan, J.; Camacho, A.E.; Ceballos, G.; Clark, J.R.; Doremus, H.; Early, R.; Etterson, J.R.; Fielder, D.; Gill, J.L.; Gonzalez, P.; Green, N.; Hannah, L.; Jamieson, D.W.; Javeline, D.; Minteer, B.A.; Odenbaugh, J.; Polasky, S.; Richardson, D.M.; Root, T.L.; Safford, H.D.; Sala, O.; Schneider, S.H.; Thompson, A.R.; Williams, J.W.; Vellend, M.; Vitt, P.; Zellmer, S. 2012. Managed Relocation: Integrating the Scientific, Regulatory, and Ethical Challenges. BioScience. 62(8): 732-743.

18. Park, A.; Talbot, C.; 2018. Information Underload: Ecological Complexity, Incomplete Knowledge, and Data Deficits Create Challenges for the Assisted Migration of Forest Trees. BioScience. 68(4): 251-263.

19. Pedlar, J.H.; McKenney, D.W.; Aubin, I.; Beardmore, T.; Beaulieu, J.; Iverson, L.; O'Neill, G.A.; Winder, R.S.; Ste-Marie, C. 2012. Placing Forestry in the Assisted Migration Debate. BioScience. 
62(9): 835-842.

20. Nagel, L.M.; Palik, B.J.; Battaglia, M.A.; D'Amato, A.W.; Guldin, J.M.; Swanston, C.W.; Janowiak, M.K.; Powers, M.P.; Joyce, L.A.; Millar, C.I.; Peterson, D.L.; Ganio, L.M.; Kirschbaum, C.; Roske, M.R. 2017. Adaptive Silviculture for Climate Change: A National Experiment in Manager-Scientist Partnerships to Apply an Adaptation Framework. Journal of Forestry. 115(3): 167-178.

21. Wang, T.; O'Neill, G.A.; Aitken, S.N. 2010. Integrating environmental and genetic effects to predict responses of tree populations to climate. Ecological Applications. 20(1): 153-163.

22. Bansal, S.; Harrington, C.A.; Gould, P.J.; St.Clair, J.B. 2015. Climate-related genetic variation in drought-resistance of Douglas-fir (Pseudotsuga menziesii). Global Change Biology. 21(2): 947-958. 23. Bansal, S.; St. Clair, J.B.; Harrington, C.A.; Gould, P.J. 2015. Impact of climate change on cold hardiness of Douglas-fir (Pseudotsuga menziesii): environmental and genetic considerations. Global Change Biology. 21(10): 3814-3826.

24. Government of British Columbia. 2018. Climate-Based Seed Transfer. Available at https://www2.gov.bc.ca/gov/content/industry/forestry/managing-our-forest... (Accessed 6/22/2018, 2018).

\section{How to cite:}


Handler, S.; Pike, C.; St. Clair, B.; 2018. Assisted Migration. USDA Forest Service Climate Change Resource Center. https://www.fs.usda.gov/ccrc/topics/assisted-migration 